\title{
Diversidade Sexual e de Gênero em Áreas Rurais, Contextos Interioranos e/ou Situações Etnicamente Diferenciadas. Novos descentramentos em outras axialidades - Apresentação
}

\author{
Estêvão Fernandes' (org.) \\ Universidade Federal de Rondônia \\ Fabiano Gontijo² (org.) \\ Universidade Federal do Pará \\ Martinho Tota3 (org.) \\ Universidade Federal do Ceará
}

Moisés Lopes4 (org.)

Universidade Federal de Mato Grosso

\footnotetext{
1 Professor Adjunto do Departamento de Ciências Sociais da Universidade Federal de Rondônia (UNIR), Professor Colaborador do Programa de Pós-Graduação em Antropologia Social da UFMT e Líder do Laboratório Amazônico de Estudos em América Latina (UNIR).

2 Professor Associado vinculado ao Programa de Pós-Graduação em Antropologia da UFPA, Professor Colaborador do Programa de Pós-Graduação em Antropologia da UFPI, líder do Grupo de Pesquisa Sexualidade, Corpo e Gênero (SEXGEN) da UFPA e Bolsista de Produtividade em Pesquisa do CNPq - Nível 2 - CA CS - Antrop., Arqueol., C. Política, Direito, Rel. Internacionais e Sociologia.

3 Professor Adjunto do Departamento de Ciências Sociais da UFC, Pós-Doutorado em Sociologia pela Universidade Federal da Paraíba (2012-2013) e Pós-Doutorado em Antropologia Social pelo Programa de Pós-Graduação em Antropologia Social do Museu Nacional/UFRJ.

4 Professor Adjunto do Departamento de Antropologia da UFMT, Professor Permanente do Programa de PósGraduação em Antropologia Social da UFMT, Líder do Grupo de Pesquisa em Antropologia do Contemporâneo Sujeitos, Sociabilidades e Visibilidades (GPAC) da UFMT e Editor Executivo da ACENO - Revista de Antropologia do Centro-Oeste.
} 
Ao propor um dossiê com o título Diversidade Sexual e de Gênero em Áreas Rurais, Contextos Interioranos e/ou Situações Etnicamente Diferenciadas - novos descentramentos em outras axialidades, nossa intenção era, em princípio, reunir um conjunto de trabalhos cujas preocupações se dessem em torno das experiências e expressões da diversidade sexual e de gênero em contextos rurais, interioranos e/ou em circunstâncias etnicamente diferenciadas.

Na chamada para esta edição da Aceno - Revista de Antropologia da UFMT, apontávamos para o fato de que no Brasil, no âmbito das Ciências Humanas e, em particular, da Antropologia, apesar da consolidação teórica e metodológica dos campos de estudos sobre ruralidade, por um lado, e, por outro, sobre gênero e sexualidade, percebe-se que pouco foram tratados, em ambos os campos, os aspectos relacionados às experiências e às expressões da diversidade sexual e de gênero nas zonas rurais brasileiras. O mesmo ocorre em relação aos contextos interioranos, caboclos e ribeirinhos e às situações etnicamente diferenciadas, indígenas e quilombolas, apesar de os estudos sobre etnicidade e sobre povos e comunidades tradicionais terem uma certa (e longa) trajetória no país, performando um campo de estudos profícuo e reconhecido internacionalmente.

Desta forma, nossos objetivos, ao propor este dossiê, eram: (1) refletir sobre a persistência da (quase) inexistência de pesquisas nas Ciências Sociais brasileiras e, em particular, em Antropologia, sobre as experiências e expressões da diversidade sexual e de gênero em contextos interioranos e rurais e em situações etnicamente diferenciadas; (2) apresentar resultados de pesquisas realizadas nesses contextos e situações (no Brasil em particular e nas Américas como um todo); e, enfim, (3) propor aportes teóricos mais adequados e planear soluções metodológicas inovadoras para lidar com essas realidades.

Nossos objetivos "eram" estes, pois aqueles pontos de partida, meses depois, transformaram-se em várias trocas de e-mails, dezenas de artigos submetidos, textos e ideias compartilhadas e ainda mais tantas inquietações. Chegamos a algumas conclusões ao longo deste percurso, as quais, rapidamente, pretendemos apontar aqui.

Primeiramente, quando propusemos este dossiê a situação política do país era outra. Ainda havia uma estrutura de Governo voltada mais diretamente para a conquista e manutenção de direitos dos vários coletivos aqui analisados. No exato momento em que escrevemos este texto, cobre-se com um véu de obscuridade - e obscurantismo - o futuro de comunidades ribeirinhas, indígenas, quilombolas, rurais, interioranas e de inúmeras pessoas que, por conta de nossa estrutura de poder radicalmente patriarcal, sexista e virifocada, encontram-se em risco por conta de sua sexualidade ou da forma como as relações de gênero historicamente se constituem cotidianamente em nosso país. O regime de verdade heteronormativo branco, masculino, metropolitano e de classe média impõe-se hoje, de forma radical, baseado numa estrutura de poder a ser não apenas compreendida, mas enfrentada, em razão dos arbitrários 
culturais sobre os quais se assentam e que legitimam a opressão institucionalizada. Tal enfrentamento pode se dar tanto desde o descentramento epistêmico, quanto no campo da utilização de redes que envolvam ativistas e pesquisadorxs para denunciar a supressão de direitos em andamento.

Isso nos leva a outro ponto: a necessidade premente de se construir, no âmbito dos estudos do gênero e da sexualidade, um novo conjunto de conceitos que deem conta desse pluriverso de afetos, sexualidades e desejos sem, necessariamente, adequá-lo ao conjunto de jargões, os quais, por conta das redes que constituem o campo dos estudos do gênero e sexualidade no país, tornaram-se gastos ou pouco adequados. A renovação epistêmica é necessária não apenas para instrumentalizar um conjunto de novas reflexões sobre nossos, até então, não-objetos, mas para a renovação do próprio campo - o que talvez resulte na formação de um outro campo, ou mesmo, se nos permitem a provocação, a um novo conceito de campo.

Como corolário, temos que tal conjunto de reflexões - chamado por nós de outras axialidades neste dossiê - necessite ser compreendido transversalmente. Neste ponto, os vários textos aqui apresentados se unem diretamente, não em relação às várias temáticas analisadas, mas por compartilharem a tendência a sair do lugar comum em relação à literatura com a qual os artigos dialogam pós-estruturalismo, queer, pós-colonialismo, colonialidade, só para citarmos alguns exemplos. São tantos exemplos de reflexões "fora do eixo hegemônico" que nos fazem questionar, até que ponto, esta hegemonia opera no âmbito de dispositivos discursivos inerentes à relações de poder dentro do campo.

Exemplo disso foi o desabafo de um dxs organizadorxs deste dossiê, via email, há alguns meses: "Fiquei curioso com a quantidade de textos sobre "gênero" (leia-se, nesse caso aqui, "mulher"), geralmente em situação de deslocamento em relação aos estudos clássicos de gênero/mulher... Isso me fez perceber que, dentro da ideia de "diversidade sexual e de gênero", há espaço para reflexões sobre outras maneiras de ser mulher e também outra maneiras de se estudar o "ser mulher"... e muito mais do que isso! Falo aqui de "mulher" mesmo, não de "feminino/feminilidade"! A implosão do feminino não destruiu totalmente a mulher, mas criou ou avivou ou fez aflorar outras formas de "ser mulher", como alguns artigos aqui parecem apontar... Estou delirando?”

Não, não era delírio. É um ponto de partida, um conjunto de interrogações preliminares - como tantos outros oferecidos nos vários textos que se seguem. Afinal, bons textos são os que nos fazem formular questionamentos que não tínhamos antes de lê-los, e se são estes questionamentos delírios, que sejam bem-vindos! Talvez estes "delírios" se devam ao fato de que boa parte das colaborações deste dossiê tenham vindo sobretudo de pessoas localizadas epistêmica ou institucionalmente nas regiões Norte e Nordeste do País, sem que houvesse uma concentração sobre realidades localizadas geográfica e/ou epistemologicamente no Centro-Sul. Ao se analisar os eixos hegemônicos politicamente no âmbito do campo dos estudos do gênero e sexualidade no País, resta evidente como a maioria dos pesquisadores das regiões Norte e Nordeste continua pouco visível ou relativamente invisibilizada - logo, um tanto quanto silenciada. Desta maneira, um dos efeitos indiretos deste dossiê pode ser o de dar uma maior visibilidade à produção das regiões Norte, Nordeste e também Centro-Oeste (para além de Brasília e Goiás). 
Finalmente, fica claro, a partir daqui, ser este número da Aceno tãosomente um primeiro passo rumo a um conjunto mais ampliado e sistematizado de ações continuadas para o estabelecimento de um rede de pesquisa(dorxs) nessas/dessas regiões, e que agregue, obviamente, também interessadxs em trabalhar questões periféricas desde este movimento de ruptura epistêmica, situados no Centro-Sul.

O conjunto das reflexões aqui publicadas nos urgem a criar uma estrutura apropriada, para além da temática da diversidade sexual e de gênero. Temos que pensar na criação de uma episteme própria: tem-se aí claramente uma articulação crítica aos instrumentos epistêmicos para pensarmos essas questões. $\mathrm{O}$ arcabouço epistemológico pensado desde os e para os centros epistêmicos hegemônicos parece insuficiente para dar conta do cruzamento de questões de sexualidade e gênero com raça, etnicidade, ruralidade, interiorianidade, religiosidade, geração, deficiência, dentre outros... Estes textos parecem ter, se tomados coletivamente, a clara mensagem de que um olhar estratigráfico para este ou aquele marcador social, isoladamente, e desde categorias euronorcêntricas, "modernas", "ocidentais", coloniais, etc., não apenas engessam toda a agência dos interlocutores das pesquisas, como encapsulam e restringem as possibilidades de análise e compreensão de seus universos. "Gênero ou raça" ou "gênero e raça" deixam de ser a questão, por exemplo, assim como "sexualidade e ruralidade" ou "sexualidade ou ruralidade": qualquer parâmetro de interpretação dessas categorias tem que problematizar o próprio contexto dentro do qual essas categorias fazem, ou não sentido - dessa forma, uma eventual contraposição ou justaposição apenas reflete padrões de poder (na academia, inclusive), em vez de colocá-los em xeque.

Boa leitura! 